\title{
IMPROVING THERMO-PHYSIOLOGICAL COMFORT OF POLYESTER/COTTON KNITS BY CAUSTIC AND CELLULASES TREATMENTS
}

\author{
Ahsan Nazir, Tanveer Hussain, Qummer Zia, Muhammad Ali Afzal \\ National Textile University, Faisalabad, Punjab PAKISTAN \\ ahsanpd@gmail.com
}

\begin{abstract}
:
Cotton is one of the most commonly used fibres for making knitwear. Some of the limitations of pure cotton knits include their tendency to shrink, relatively limited durability, and poor wash and wear properties. In order to overcome these limitations knitwear are also produced from polyester and cotton blends, however, at the cost of reduction in comfort properties. The objective of this study was to improve the thermo-physiological comfort properties of knits made from polyester/cotton $(P / C)$ blends through simple chemical and biological treatments. The specimens of $P / C$ knits were subjected to treatments with caustic soda solutions and the cellulase enzymes. It was found that the air permeability and perspiration management properties of $P / C$ knits can be significantly improved by appropriate caustic treatment. However, the biological treatment with cellulase enzymes is comparatively less effective in making any improvement in the thermo-physiological comfort properties of $P / C$ knits.
\end{abstract}

\section{Keywords:}

Comfort Moisture management Cotton/polyester

\section{Introduction}

Comfort is defined by Slater as "a pleasant state of psychological, physiological and physical harmony between a human being and the environment" [1]. It is a broader term and includes three main subclasses, i.e. sensorial, psychological and thermo-physiological comfort [2]. The thermo-physiological comfort, discussed here, is a combination of thermal balance and physical/biochemical function of the body. Among many other factors, the thermo-physiological comfort is affected by the heat flow through the clothing and its moisture management capability [3, 4]. Air permeability of a clothing material also has a strong impact on thermo-physiological comfort. All these properties are interrelated and they further depend on many other factors including the characteristics of fibres, yarns, the structure of fabric produced from them and the subsequent treatments $[3,5-8]$.

Different fibre materials offer different types of comfort properties. However, selection of fibre depends on a variety of factors. For example, polyester/cotton $(\mathrm{P} / \mathrm{C})$ blended fabrics rapidly gained importance, mainly due to the fact that both the fibres, when blended, compensate the shortcomings of each other, thus providing better properties than those provided by pure cotton or pure polyester fabrics [9]. However, the use of P/C fabrics in active wear such as sportswear is still limited primarily because of their lower moisture management capability.

Many approaches have been utilized to improve the comfort properties of polyester and cotton fabrics. Caustic treatment of polyester yarns was found to improve their wicking properties [10]. Similarly, it resulted in improved air permeability and better drape of polyester fabrics [11,12]. These improvements could be attributed to the fact that caustic treatment modifies the surface of the polyester fibre by hydrolysis, which adds up hydroxyl and carboxyl groups on it, thus allowing it to attract more water reducing its inherent hydrophobicity. Moreover, it also increases the fibre fineness [7]. Both these factors can thus improve the moisture vapour transfer properties, air permeability and heat flow of the caustic treated polyester fabrics [13-15]. In the same manner, enzymatic treatment of cotton fabrics degrade the fibre surface, resulting in finer fibres without cuticle and thus improves moisture absorption capability and air permeability of fabric $[16,17]$. Some cellulase enzymes produce pathways on the surface of cotton fibres, improving their moisture transport capacity [18]. Both the caustic and cellulase treatments also affect the number of hydrophilic groups in polyester and cotton fibres as both degrade the fibre. Increasing the number of hydrophilic groups increases the absorbency but decreases the moisture transport capability [19]. Therefore, any agent that affects any of the above-discussed properties will affect the overall comfort properties of P/C fabrics. This study was undertaken to observe the effect of caustic and cellulase treatment on comfort properties of $\mathrm{P} / \mathrm{C}$ knitted fabric based on the fact that these treatments affect the fineness of fibre, their hydrophilicity and the permeability of fabric.

\section{Materials and method}

\section{Fabric}

A P/C single jersey knitted fabric, comprising $52 \%$ polyester and $48 \%$ cotton as an intimate blend, was used in this study. The area density of the fabric was $143 \mathrm{~g} / \mathrm{m}^{2}$ with 44 courses/ in. and 35 wales/in. 


\section{Chemicals}

The chemicals employed in this study are listed below.

- Hostapal NI-Extra, a non-ionic detergent/emulsifying agent by Clariant, Pakistan.

- Hydrogen peroxide (35\%, commercial grade), by Sitara Peroxide Pakistan Ltd.

- Stabilizer CT, a bleaching bath stabilizer by Chromatex, Pakistan.

- Caustic Soda flakes (commercial grade), by Engro Chemicals Pakistan Ltd.

- Cellusoft CR, a commercial grade cellulase enzyme by Novozyme, Pakistan.

\section{Machinery and equipment}

The equipments employed to execute this work are listed below.

- Winch WD-100 by Tsujii Machine Manufacturing Co. Ltd, Japan.

- Moisture Management Tester by SDL Atlas, UK.

- Air Permeability Tester by SDL Atlas, UK.

- Bursting Strength Tester by James H. Heals, UK.

\section{Fabric scouring and bleaching}

The greige fabric was washed using $0.8 \mathrm{~g} / \mathrm{l}$ Hostapal NI Extra at $65^{\circ} \mathrm{C}$ to emulsify the natural and added knitting oils and to remove any type of dust and dirt in it. The fabric was subjected to one-bath scouring and bleaching process at $90^{\circ} \mathrm{C}$ for 40 min, using $6 \mathrm{~g} / \mathrm{l}$ hydrogen peroxide, $4 \mathrm{~g} / \mathrm{l}$ caustic soda and $1 \mathrm{~g} / \mathrm{l}$ Stabilizer CT. The fabric was then rinsed with water at ambient temperature, followed by a hot wash at $95^{\circ} \mathrm{C}$ for $20 \mathrm{~min}$.

\section{Fabric treatment with caustic soda}

The polyester component of the P/C fabric under study was modified with caustic soda treatment. This treatment was performed at varying intensities. The difference in intensity was achieved by changing the time of treatment with fixed caustic soda concentration and temperature. Three bleached fabric samples were treated with $100 \mathrm{~g} / \mathrm{l}$ caustic soda at $95^{\circ} \mathrm{C}$ for 10 ,
20 and $30 \mathrm{~min}$, respectively, followed by washing, neutralizing and drying in ambient air.

\section{Fabric treatment with cellulase}

Similarly, the cotton component in blend was modified with cellulase enzyme treatment. Three bleached fabric samples were treated with $3 \mathrm{~g} / \mathrm{l}$ Cellusoft $\mathrm{CR}$ (cellulase enzyme) at $55^{\circ} \mathrm{C}$ for 15,30 and $45 \mathrm{~min}$, respectively, followed by washing and drying at ambient temperature.

\section{Testing of the treated samples}

All the samples were conditioned overnight in standard environment before testing. Air permeability of the fabric was tested according to ASTM D737 using SDLAtlas air permeability tester. The moisture management properties of the samples were tested as described in AATCC 195-2009 using SDL Atlas moisture management tester. Based on the fact that caustic and enzymatic treatments may also affect the strength of the fabric, the effect of these treatments on bursting strength was also studied. It was determined according to ASTM D3786 using James $\mathrm{H}$. Heals bursting strength tester.

\section{Results and discussion}

\section{Effect of caustic and cellulase treatment on fabric air permeability}

The effect of caustic and cellulase treatment on the air permeability of the treated fabric is shown in Figure 1. From analysis of variance (ANOVA), it was concluded that caustic treatment at different process times results in statistically significant improvement in air permeability while the enzyme treatment does not have a significant impact on it. The correlation analysis further indicated that the fabric air permeability has strong positive correlation with reduction in fabric area density by the caustic treatment. The caustic treatment causes reduction in the diameter of the polyester fibres, leading to increase in the fabric porosity which subsequently improves the air permeability of fabric (Figure 2). The cellulase treatment results in the removal of cotton fibres protruding out from the

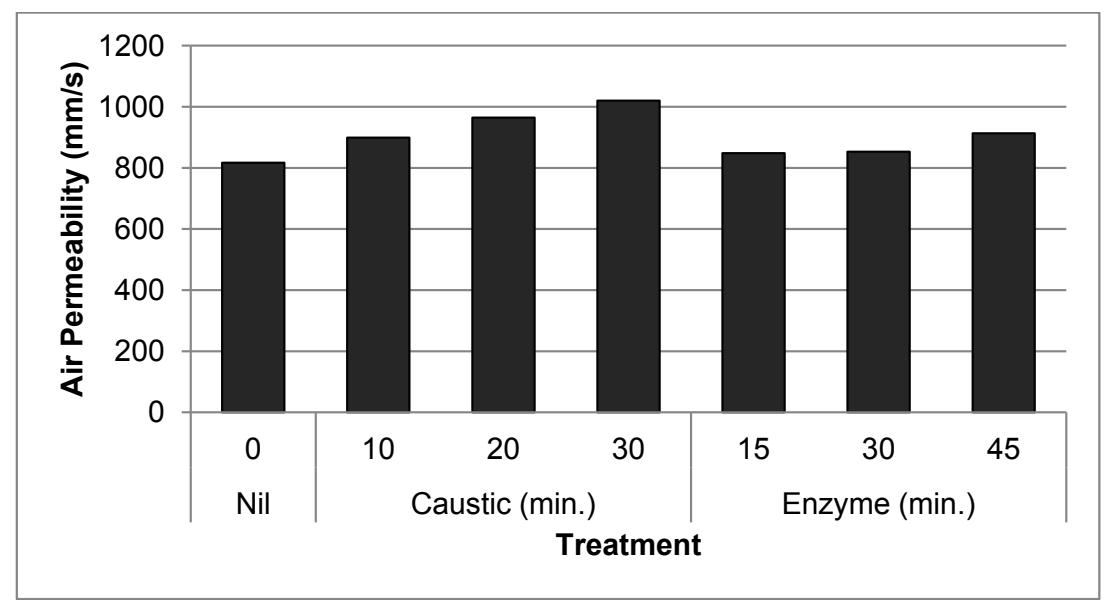

Figure 1. Effect of caustic and cellulase treatment on fabric air permeability 
fabric surface while the fibres embedded deep in the fabric structure remain unaffected, thus resulting in improvement in fabric porosity.

\section{Effect of caustic and cellulases treatment on fabric moisture management properties}

Figure 3 shows the effect of caustic and cellulase enzyme treatment on wetting time of the treated samples for both top and bottom sides. It is clear that the caustic treatment does not affect the fabric wetting time significantly, while the enzyme treatment increases the wetting time. It seems that the presence of some protruding cotton fibres at the fabric surface helps in quicker wetting of fabric but when these protruding hydrophilic cotton fibres are removed by the cellulase enzyme treatment, the wetting time of the fabric increases.
Water absorption rate at the top and bottom faces of the treated fabric samples is given in Figure 4. It is evident that the caustic treatment results in improved absorption rate, which increases with increase in the treatment time. However, increase in the absorption rate is not significant in case of cellulase treatment. Higher absorption rates for caustic treated fabrics may be explained to occur due to increase in interfibre spaces and porosity in the fabrics caused due to reduction in the polyester fibre diameter. The diameter of polyester fibres decreases because of the alkaline hydrolysis with caustic treatment. Since the action of enzyme is limited to the fabric surface only, absorption rate remains almost unchanged due to little increase in fabric pore size.

The increase in the fabric porosity due to increased interfibre spaces also results in greater movement of the water within the
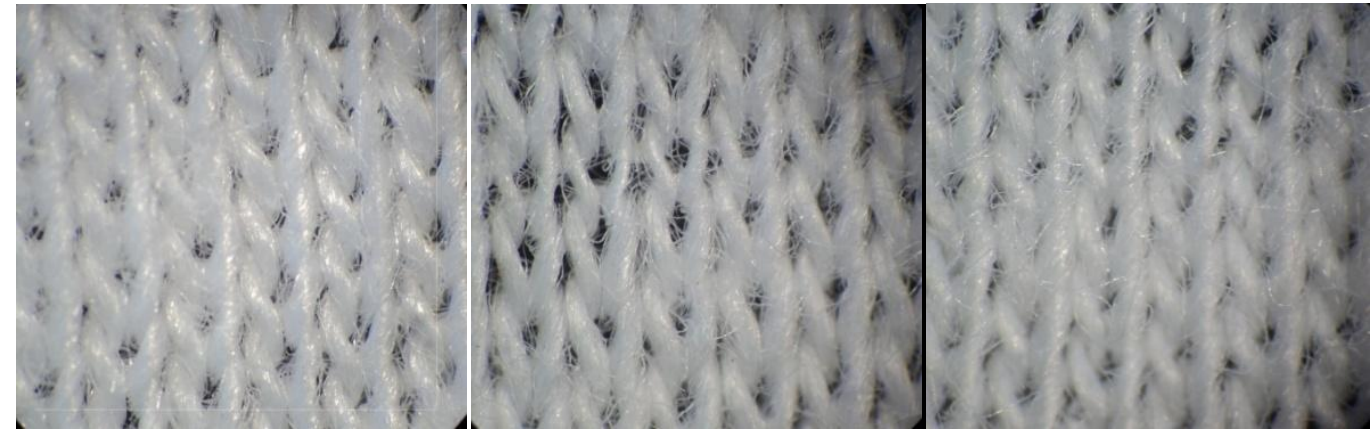

Figure 2. From left-to-right: untreated sample; caustic treated sample; cellulase treated sample

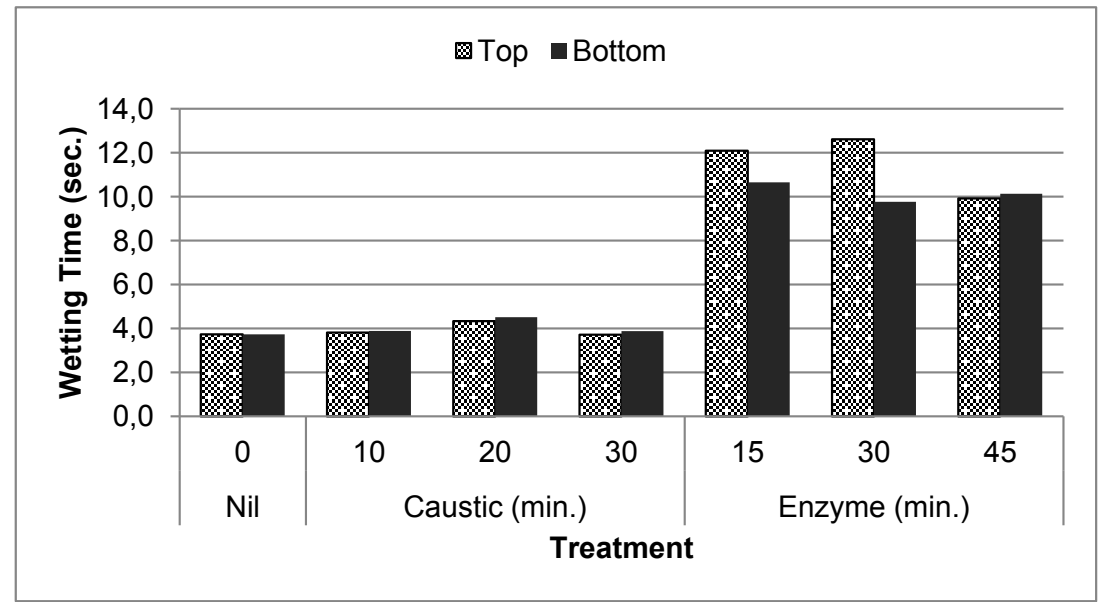

Figure 3. Effect of caustic and cellulase treatment on fabric wetting time

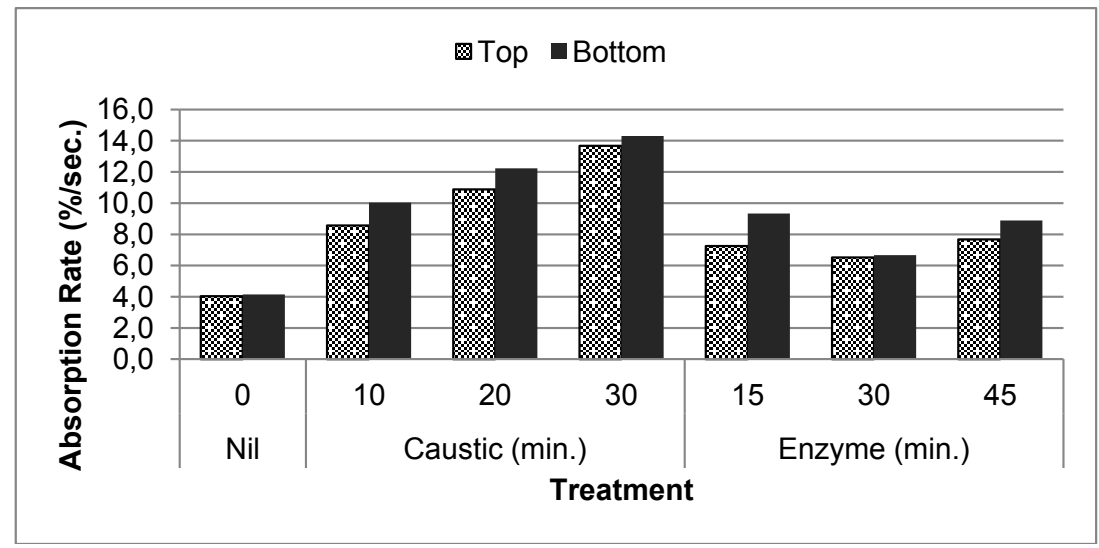

Figure 4. Effect of caustic and cellulase treatment on fabric water absorption rate 
fabric, leading to higher wetted radius as shown in Figure 5. However, the cellulase enzyme treatment for 15 min results in no increase in wetted radius, whereas increase in cellulase treatment time steadily increases the fabric wetted radius. It appears that the removal of protruding cotton fibres results in smoother fabric surface that facilitates the water spreading, although not comparable to that achieved by caustic treatment, which also increases the fabric's internal porosity.

Figure 6 shows that caustic treatment significantly increases the overall moisture management capability (OMMC) of the fabric. However, cellulase enzyme treatment decreases the
OMMC. This may be attributed to higher absorption rate, better water spreading and accumulative one-way transport index in case of the fabrics, which have undergone caustic treatment.

\section{Effect of caustic and cellulases treatment on fabric bursting strength}

Figure 7 demonstrates that improvement in air permeability and moisture management properties is achieved at the cost of bursting strength of the fabric. The bursting strength of the caustic treated samples decreases due to decrease in fabric area density as a result of polyester fibre hydrolysis.

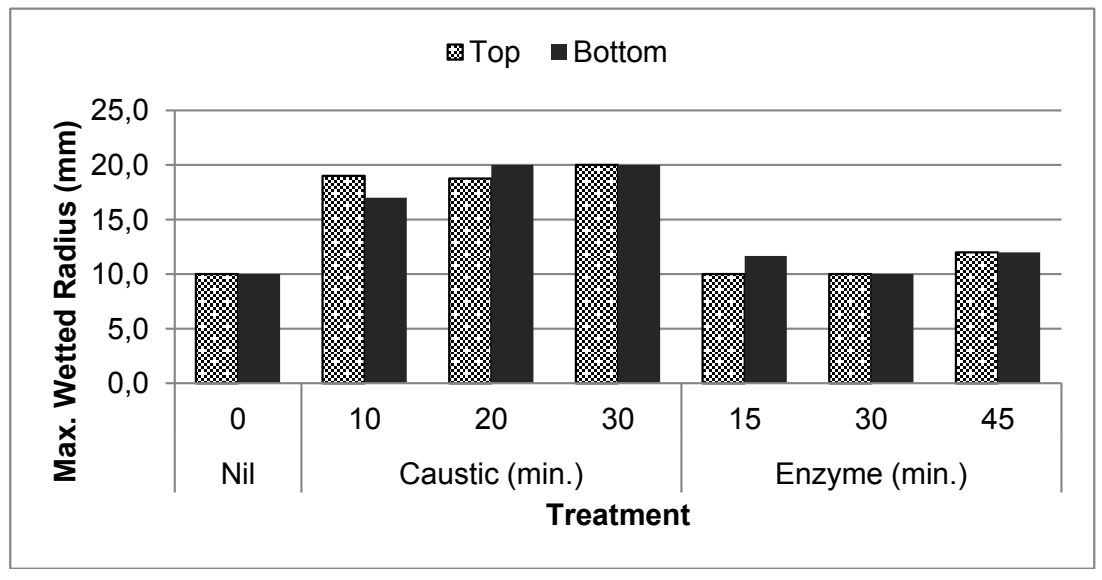

Figure 5. Effect of caustic and cellulase treatment on fabric maximum wetted radius

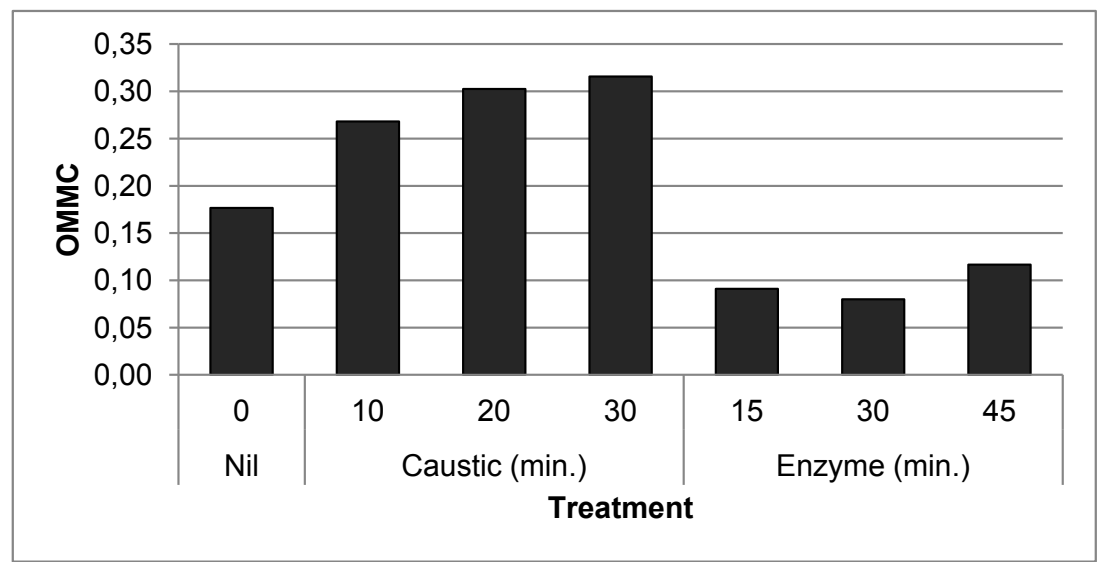

Figure 6. Effect of caustic and cellulase treatment on fabric OMMC

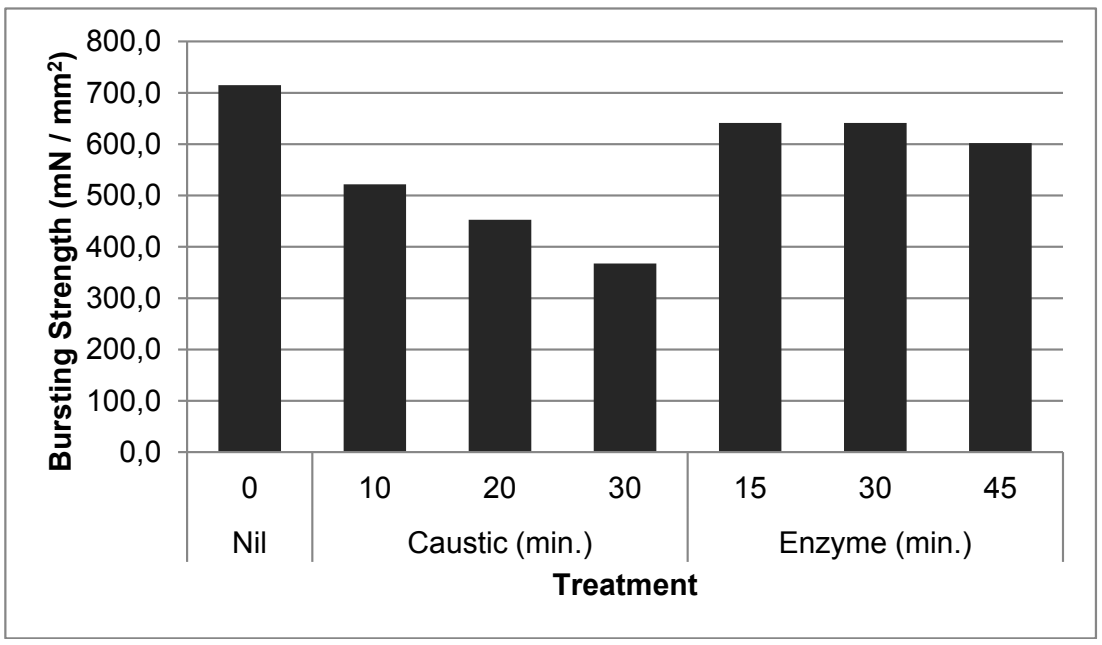

Figure 7. Effect of caustic and cellulase treatment on fabric bursting strength 
However, an optimum level of treatment can produce fabric with enhanced moisture management and air permeability without substantial loss in bursting strength. In a future work, in addition to optimization, the authors intend to compare the air permeability, the moisture management and the bursting strength of cotton and caustic-treated polyester/cotton blended fabric knitted at the same fabric density from the yarns of the same linear density.

\section{Conclusions}

The effect of caustic and cellulase treatment on some aspects of thermo-physiological comfort of polyester/cotton knitted fabrics was studied. It was concluded that caustic treatment is very effective in improving fabric air permeability and moisture management properties of treated fabrics at the cost of bursting strength of the fabric, which may be kept to acceptable levels using mild treatment conditions. While cellulase treatment is effective in fabric surface smoothening through removal of cotton protruding fibres, its effectiveness for improving thermophysiological comfort is limited for the concentrations and the treatment times used in this study.

\section{References}

[1] Slater, K. (1985). Human Comfort. C.C. Thomas.

[2] Nida, O. and Arzu, M. (2007). Thermal comfort properties of some knitted structures. Fibres and textiles in Eastern Europe, 15(5),

[3] Ciesielska, I., Mokwiński, M., and Orłowska-Majdak, M. (2009). Influence of different kind of clothing material on selected cardiovascular, respiratory and psychomotor parameters during moderate physical exercise. International Journal of Occupational Medicine and Environmental Health, 22(3), 215-226.

[4] Das, A., Alagirusamy, R., and Kumar, P. (2011). Study of heat transfer through multilayer clothing assemblies: a theoretical prediction. AUTEX Research Journal, 11, 5460.

[5] Yoon, H. and Buckley, A. (1984). Improved Comfort Polyester Part I: Transport Properties and Thermal Comfort of Polyester/Cotton Blend Fabrics. Textile Research Journal, 54(5), 289-298.

[6] Onofrei, E., Rocha, A. M., and Catarino, A. (2011). The influence of knitted fabrics' structure on the thermal and moisture management properties. Journal of Engineered Fibers and Fabrics, 6(4), 10-22.

[7] Yoon, H., Sawyer, L., and Buckley, A. (1984). Improved comfort polyester Part II: Mechanical and surface properties. Textile Research Journal, 54(6), 357-365.

[8] Bivainyte, A., Mikucioniene, D., and Kerpauskas, P. (2012). Investigation on Thermal Properties of Double-Layered Weft Knitted Fabrics. Materials Science, 18(2), 167-171.

[9] Su, C.-I., Fang, J.-X., Chen, X.-H., and Wu, W.-Y. (2007). Moisture absorption and release of profiled polyester and cotton composite knitted fabrics. Textile Research Journal, 77(10), 764-769.

[10] Vigneswaran, C. and Anbumani, N. (2011). Partial alkaline hydrolysis treatment on the physical characteristics of polyester rotor spun yarns. The Journal of The Textile Institute, 102(2), 140-149.

[11] Sanders, E. M. and Zeronian, S. H. (1982). An analysis of the moisture $\square$ related properties of hydrolyzed polyester. Journal of Applied Polymer Science, 27(11), 4477-4491.

[12] Needles, H. L. (1985). How Alkali treatments Affect Selected properties of Polyester, Cotton and Polyester Cotton Fabrics. Textile Chemist and Colorist, 17(9), 177-180.

[13] Nayaka, R., Punj, S., Chatterjee, K., and Behera, B. (2009). Comfort properties of suiting fabrics. Indian Journal of Fibre \& Textile Research, 34, 122-128.

[14] Srinivasan, J., Ramakrishnan, G., Mukhopadhyay, S., and Manoharan, S. (2007). A study of knitted fabrics from polyester microdenier fibres. Journal of the Textile Institute, 98(1), 31-35.

[15] Kim, S. H., Lee, J. H., Lim, D. Y., and Jeon, H. Y. (2003). Dependence of sorption properties of fibrous assemblies on their fabrication and material characteristics. Textile Research Journal, 73(5), 455-460.

[16] Li, Y. and Hardin, I. R. (1998). Treating cotton with cellulases and pectinases: effects on cuticle and fiber properties. Textile Research Journal, 68(9), 671-679.

[17] Zhong, W., Ding, X., and Tang, Z. (2001). Modeling and analyzing liquid wetting in fibrous assemblies. Textile Research Journal, 71(9), 762-766.

[18] Lee, I., Evans, B. R., and Woodward, J. (2000). The mechanism of cellulase action on cotton fibers: evidence from atomic force microscopy. Ultramicroscopy, 82(1), 213221.

[19] Das, B., Das, A., Kothari, V., Fanguiero, R., and Araujo, M. $D$. (2009). Moisture flow through blended fabrics-Effect of hydrophilicity. Journal of Engineered Fibers and Fabrics, 4(4), 20-27. 